\title{
Aeromedical Transport Operations Using Helicopters during the 2016 Kumamoto Earthquake in Japan
}

\author{
Tomokazu Motomura ${ }^{1}$, Atsushi Hirabayashi ${ }^{1}$, Hisashi Matsumoto ${ }^{1}$, Nobutaka Yamauchi ${ }^{1}$, \\ Mitsunobu Nakamura', Hiroshi Machida², Kenji Fujizuka², Naomi Otsuka ${ }^{2}$, \\ Tomoko Satoh ${ }^{4}$, Hideaki Anan ${ }^{5}$, Hisayoshi Kondo ${ }^{6}$ and Yuichi Koido ${ }^{6}$ \\ ${ }^{1}$ Shock and Trauma Center, Nippon Medical School Chiba Hokusoh Hospital, Chiba, Japan \\ ${ }^{2}$ Japanese Red Cross Maebashi Hospital, Gunma, Japan \\ ${ }_{3}^{3}$ Japanese Red Cross Kumamoto Hospital, Kumamoto, Japan \\ ${ }^{4}$ Saga-ken Medical Centre, Koseikan Hospital, Saga, Japan \\ ${ }^{5}$ Fujisawa City Hospital, Kanagawa, Japan \\ ${ }^{6}$ Institute for Clinical Research National Disaster Medical Center, Tokyo, Japan
}

\begin{abstract}
More than 6,000 people died in the Great Hanshin (Kobe) Earthquake in 1995, and it was later reported that there were around 500 preventable trauma deaths. In response, the Japanese government developed the helicopter emergency medical service in 2001, known in Japan as the "Doctor-Heli" (DH), which had 46 DHs and 2 private medical helicopters as of April 2016. DHs transport physicians and nurses to provide pre-hospital medical care at the scene of medical emergencies. Following lessons learned in the Great East Japan Earthquake in 2011, a research group in the Ministry of Health, Labour and Welfare developed a command and control system for the DH fleet as well as the Disaster Relief Aircraft Management System Network (D-NET), which uses a satellite communications network to monitor the location of the fleet and weather in real-time during disasters.

During the Kumamoto Earthquake disaster in April 2016, 75 patients were transported by 13 DHs and 1 private medical helicopter in the first 5 days. When medical demand for the DHs exceeded supply, 5 patients, 8 patients, and 1 patient were transported by Self-Defense Force, Fire Department, and Coast Guard helicopters, respectively. Of the 89 patients who were transported, 30 (34\%) had trauma, $3(3 \%)$ had pulmonary embolisms caused by sleeping in vehicles, and $17(19 \%)$ were pregnant women or newborns. This was the first time that the command and control system for aeromedical transport and DNET, established after the Great East Japan Earthquake in 2011, were operated in an actual large-scale disaster. Aeromedical transport by DHs and helicopters belonging to several other organizations was accomplished smoothly because the commanders of the involved organizations could communicate directly with each other in person within the Aviation Coordination Section of the prefectural government office.

However, ongoing challenges in the detailed operating methods for aeromedical transport were highlighted and include improving shared knowledge and training across the organizational framework. These are particularly important issues to address given the Nankai Trough and Tokyo inland earthquakes that are predicted for the near future in Japan. (J Nippon Med Sch 2018; 85: 124-130)
\end{abstract}

Key words: aeromedical transport, command and control, dynamic location monitoring, earthquake, helicopter

Correspondence to Tomokazu Motomura, MD, Shock and Trauma Center, Nippon Medical School Chiba Hokusoh Hospital, 1715 Kamagari, Inzai, Chiba 270-1694, Japan

E-mail: xcjwg823@yahoo.co.jp

Journal Website (http://www2.nms.ac.jp/jnms/) 


\section{Introduction}

In Japan, following evaluation of the disaster response efforts after the 1995 Great Hanshin Earthquake, in which there were over 6,000 fatalities, including more than an estimated 500 preventable trauma deaths ${ }^{1}$, the Japanese Ministry of Health, Labour and Welfare (MHLW) developed a "physician on-board" helicopter system, the "Doctor-Heli" (DH) service. A DH is dispatched within 3 minutes of receiving a deployment request from the fire department. It transports physicians and nurses to provide pre-hospital medicine at the scene and then transports the patient to hospital immediately. As of April 2016, the DH network operated a total of 46 helicopters (Fig. 1).

In 2001, the MHLW also established a disaster medical assistance team (DMAT) composed of mobile and trained medical teams that can be rapidly deployed during the acute phase (within 72 hours) of a disaster. As of 2016, there were approximately 1,500 DMAT members in Japan. Since 2003, the DMAT Research Group has investigated the utilization and command of the $\mathrm{DH}$ fleet in disaster situations. Later, after the 2011 Great East Japan Earthquake, in efforts to address the lessons learned during the disaster response efforts, an MHLW research group developed a command and control system for the DH fleet as well as the Disaster Relief Aircraft Management System Network (D-NET), which uses a satellite network to monitor in real-time the location of helicopters operating during a disaster.
While it is known that medical transport using helicopters is often extremely useful in earthquake disaster situations ${ }^{1}$, enabling patients to be transported across a wide area despite roads being blocked, damaged, or destroyed, coordinating systematic aeromedical operations involving helicopters from multiple disaster response organizations is not easy. Moreover, although some reports have described helicopter emergency medical service activities or aeromedical transport using army helicopters in disaster situations ${ }^{2-4}$, there is currently not much information available in the literature on the command and control systems or methods of operation of aeromedical transport that have been used.

This report describes in detail the benefits of and issues found with the command and control system for aeromedical transport that was used to deploy and control DHs and helicopters from multiple organizations during disaster response activities following the $2016 \mathrm{Ku}-$ mamoto Earthquakes in Japan.

\section{Report}

Assembling the DHs, Implementing the Command and Control System of DHs, and Collaborating with Helicopters from Multiple Organizations

At 01:25 on April 16, 2016, the second and main earthquake (magnitude 7.3) hit Kumamoto Prefecture, causing widespread damage to the island of Kyushu, western Japan. In total, 161 people died and 2,692 were injured (1,087 severely and 1,605 moderately) in the main earth-

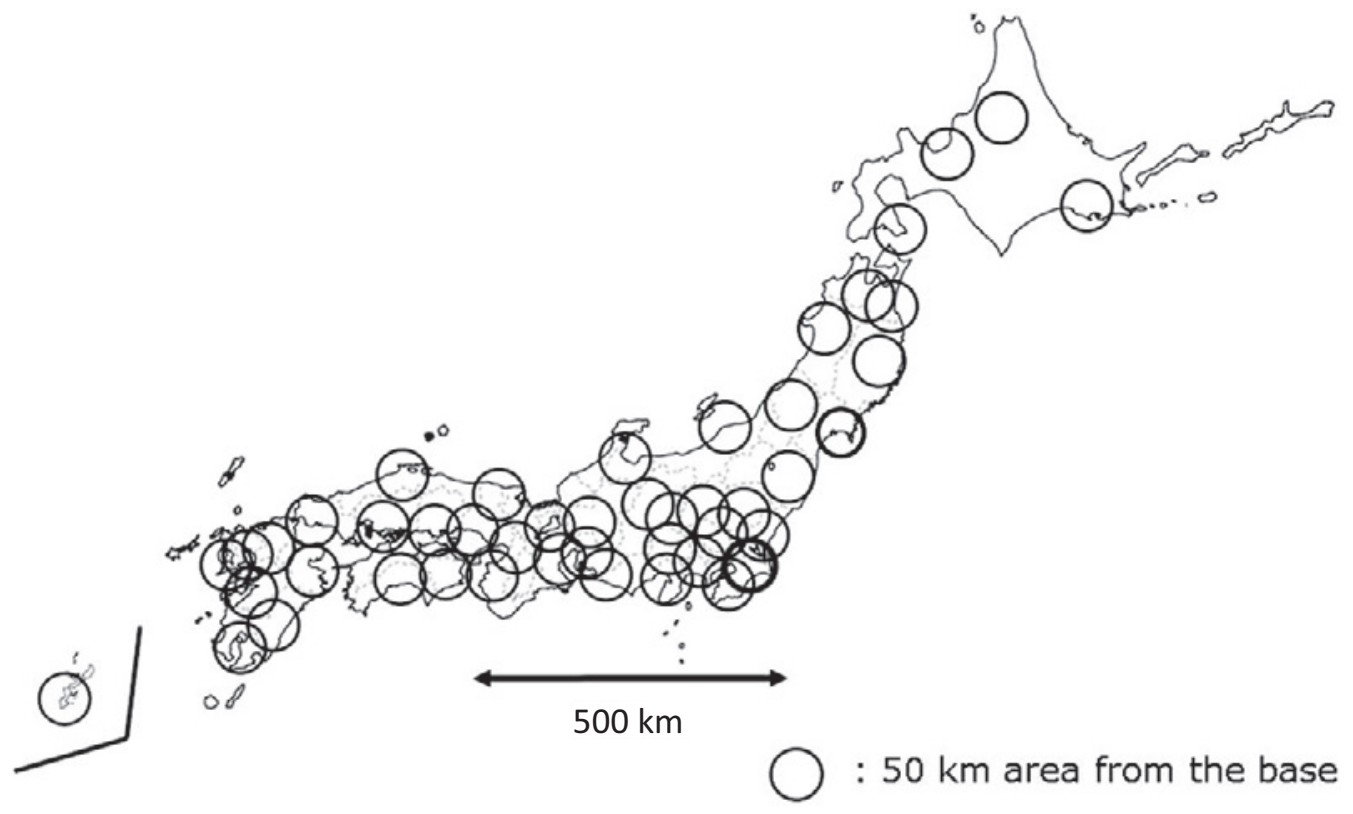

Fig. 1 The 50-km circles are centered on the base hospitals for the Doctor-Heli (DH) service in Japan. Forty-six DHs are in operation as of April 2016. 


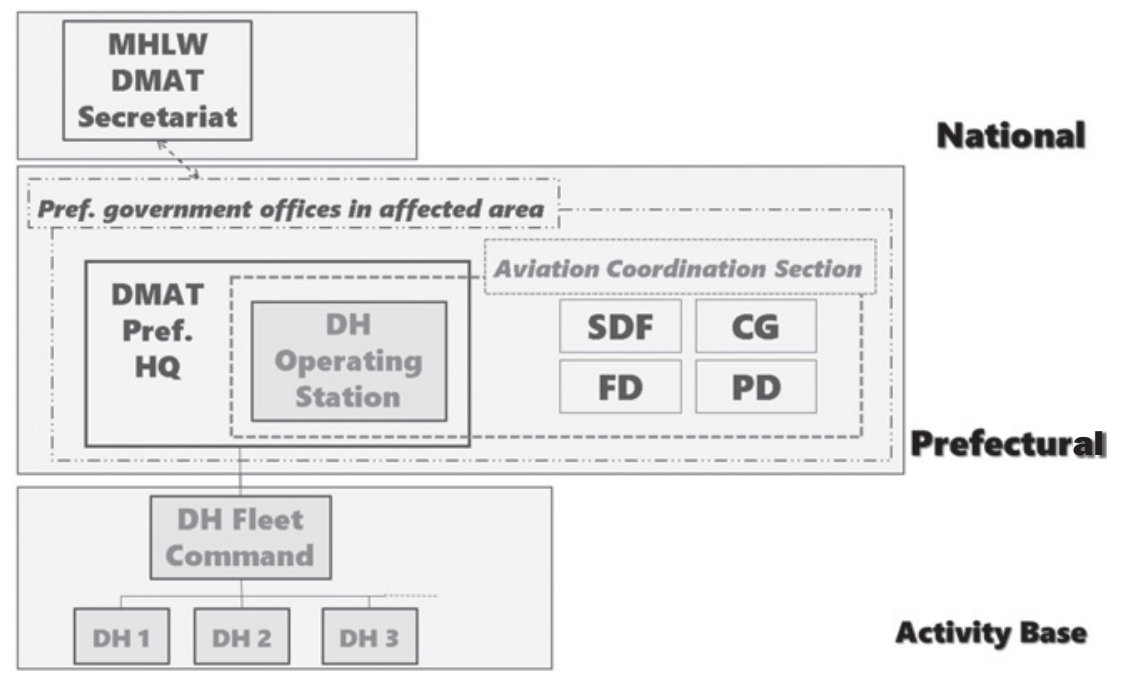

Fig. 2 The command system for the DH network after they were assembled for deployment in the disaster area. In the prefectural government offices of the affected area, the DH Operations Station was set up in the DMAT prefectural headquarters. In the command and control system, information was shared by the ACS of Kumamoto Prefectural Government with the SDF, FD, CG, and PD.

MHLW: Ministry of Health, Labour and Welfare; DMAT: Disaster Medical Assistance Team; Pref: Prefectural

DH: Doctor-Heli; HQ: headquarters; FD: Fire Department; CG: Coast Guard; SDF: Self-Defense Force; PD: Police Department

quake ${ }^{5}$.

Figure 2 shows the overall command and control structure for aeromedical operations that was in operation for this disaster. Just after the earthquake, the MHLW nominated special DMAT members, who were supervisory DMAT certification holders recognized by the MHLW and had sufficient knowledge and experience as commanders, from across Japan to serve as commanders of several DMAT activity bases in the affected area. Following an order to establish a DH Operations Station (DOS), commanders of the DH fleet immediately traveled to the DMAT headquarters of Kumamoto Prefectural Government. In addition, national headquarters of the DH fleet, located in the DMAT Secretariat of MHLW, requested coordinating base hospitals in neighboring area blocks (Kyushu, Chushikoku, and Kansai) to send some of their DHs to the disaster area. In total, 13 DHs and 1 private medical helicopter were dispatched to the affected area (Fig. 3). The DOS set up by Kumamoto Prefectural Government started to gather information about the DHs and helicopters from other organizations that were to participate in medical transport. It also gathered information on fuel and parking spaces available and data on medical demand, receiving hospitals within and outside the prefecture, and topography and climate. In principal, demands for medical transport that cannot be met in the local disaster area are collected and handled by headquarters in the prefectural government office. Then, DOS arranged for the helicopters to refuel at $\mathrm{Ku}$ mamoto Airport in addition to the usual DH base hospital sites and to park at Kumamoto Airport and an athletics ground.

The headquarters of DMAT in the prefectural government office requested aeromedical transport to DOS for cases where emergency treatment was required or locations where land movement was difficult due to landslides or other damage. Other patients were transported by ground ambulance or other vehicles. DOS decided which helicopter to use depending on a patient's medical condition. The use of a DH was deemed appropriate in severe, urgent, or physiologically unstable patients where curative treatment in hospitals outside the affected area was needed immediately, and the DH Fleet Command (DFC), a subordinate organization, was asked to arrange the DH. However, demands for aeromedical transport exceeded the carrying capacity of the DHs. The prefecture is mandated to set up an Aviation Coordination Section (ACS) within the prefectural government and to coordinate cooperation to optimize the aeromedical transport resources of multiple organizations in the event of a 


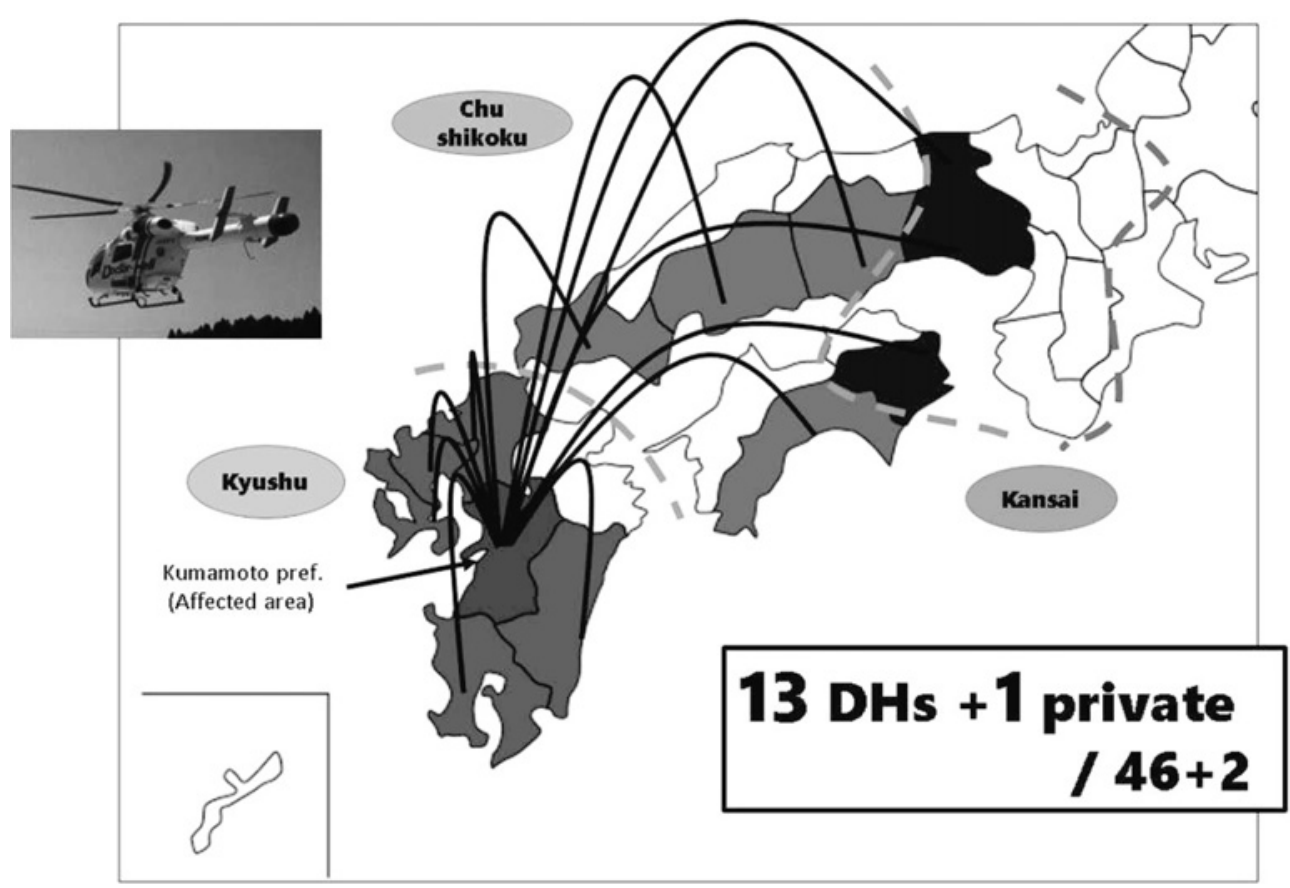

Fig. 3 The areas and prefectures from which Doctor-Helis (DHs) were dispatched. Thirteen DHs and 1 private medical helicopter were assembled for deployment in the affected area and provided aeromedical transport for 5 days.

Table 1 Details of patients transported using helicopters in the 2016 Kumamoto Earthquake disaster

\begin{tabular}{|c|c|c|c|c|c|c|c|c|}
\hline & \multicolumn{5}{|c|}{ Patients transported } & \multicolumn{2}{|c|}{ Destination } & \multirow{3}{*}{ Total } \\
\hline & \multirow{2}{*}{ PWNg } & \multicolumn{2}{|c|}{ Internal } & \multirow{2}{*}{ Trauma } & \multirow{2}{*}{ Unknown } & \multirow{2}{*}{ Inside $^{d}$} & \multirow{2}{*}{ Outside $^{e}$} & \\
\hline & & Disease & $\mathrm{PE}^{\mathrm{f}}$ & & & & & \\
\hline $\mathrm{FD}^{\mathrm{c}}$ & 1 & 6 & 0 & 1 & 0 & 1 & 7 & 8 \\
\hline$C G^{\mathrm{a}}$ & 0 & 1 & 0 & 0 & 0 & 1 & 0 & 1 \\
\hline SDFh & 0 & 5 & 0 & 0 & 0 & 0 & 5 & 5 \\
\hline $\mathrm{DH}^{\mathrm{b}}$ & 16 & 25 & 3 & 29 & 2 & 18 & 57 & 75 \\
\hline Total & 17 & 37 & 3 & 30 & 2 & 20 & 69 & 89 \\
\hline $\begin{array}{l}{ }^{\text {aC Coast }} \\
\text { bDocto } \\
\text { cFire D } \\
\text { din the } \\
\text { eOutsi } \\
\text { PPulmo } \\
\text { gPregn } \\
\text { hJapan }\end{array}$ & $\begin{array}{l}\text { uard } \\
\text { Heli servi } \\
\text { artment } \\
\text { fected ar } \\
\text { the affect } \\
\text { ary embol } \\
\text { t women } \\
\text { lf-Defens }\end{array}$ & $\begin{array}{l}\text { area } \\
\text { m newborn } \\
\text { Forces }\end{array}$ & & & & & & \\
\hline
\end{tabular}

large-scale disaster requiring a multi-organization response (Fig. 2). The ACS meets regularly and participating organizations exchange information about the number of helicopters available for medical transport and then prioritize. DMAT can request medical transport from other organizations if necessary. DOS also consulted with DMAT headquarters in the neighboring nondisaster-affected prefectures and arranged for patients to be transported to hospitals in those prefectures. DOS re- quested that these prefectures accept all patients transported by an individual $\mathrm{DH}$ at a single hospital in order to reduce burden on DOS or DFC by having to coordinate the DH's movements to multiple hospitals.

For the deployment of DHs, DOS requested DFC to arrange the deployment. DFC was set up at Kumamoto Red Cross Hospital, the base hospital for Kumamoto DH service. In total, 13 of Japan's 46 operational DHs and 1 of 2 private medical helicopters located within $300 \mathrm{~km}$ of 


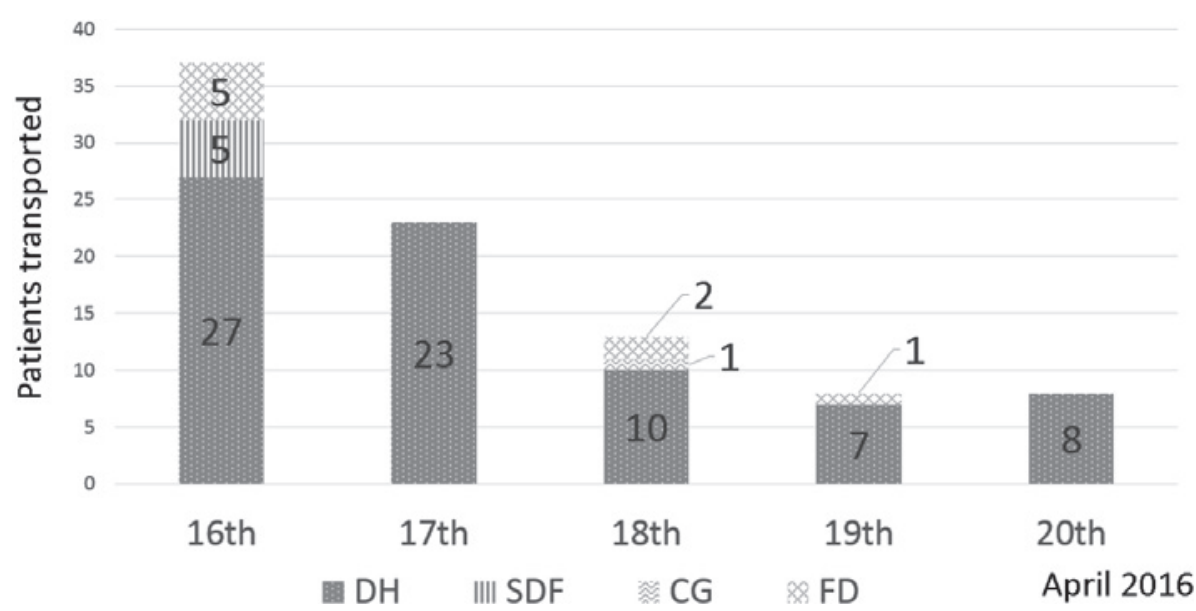

Fig. 4 The daily number of patients who received aeromedical transport each by organization.

DH: Doctor-Heli; SDF: Self-Defense Forces; CG: Coast Guard; FD: Fire Department

the affected area were assembled to the affected area according to advance directives and were able to provide aeromedical transport for 75 patients in the first 5 days after the main earthquake (Table 1). From very early in the disaster relief efforts, the ACS at Kumamoto Prefectural Government told the DOS exactly how many helicopters from the other organizations were available. For example, 80 helicopters including 3 large Boeing $\mathrm{CH}-47$ Chinooks from the Self-Defense Forces (SDF), 16 from the FD, and 4 from the CG were available at 13:00 on the second day of the disaster (April 17). The number of patients who received aeromedical transport using helicopters was highest on the day of the earthquake and then decreased daily thereafter (Fig. 4).

A total of 89 patients were successfully transported by helicopters under the $\mathrm{DH}$ command system: 75 by DHs, 5 by SDF helicopters, 8 by FD helicopters, and 1 by a CG helicopter (Table 1). Thirty of these patients (34\%) had trauma and were injured directly by the earthquake, 17 $(19 \%)$ were pregnant women or newborns, and $3(3 \%)$ were patients with pulmonary embolism due to sleeping in their vehicles. Sixty-nine patients (78\%) were transported to outside of Kumamoto Prefecture.

\section{Communications}

Usual communication methods including mobile phone and wireless internet networks were available except for just several hours immediately after the earthquake. This meant that aeromedical transport information could be shared via the internet-based emergency medical information system (EMIS) that was specifically developed to share disaster-related information about damage and medical demand in hospitals in the affected areas and DMAT activities.

The overall picture of damage and medical demand was determined from EMIS and then a request for aeromedical transport was made by telephone or FAX to DOS. Moreover, information about the real-time location of DHs and FD helicopters was monitored using D-NET. This satellite communications network was developed by Japan Aerospace Exploration Agency, Weathernews Inc., and DMAT after the 2011 Great East Japan Earthquake (Fig. 5) ${ }^{6}$. During a disaster, geolocation data that are not normally disclosed by the individual organizations are shared among the relevant participating organizations by D-NET. This enables data to be gathered using almost all transmitters in Japan. Thus, D-NET enabled the commanders to know the location of DHs and FD helicopters and current weather conditions in real-time using a laptop, which meant that operations could be managed efficiently and safely by DOS and DFC.

\section{Discussion}

The literature contains few detailed reports on the command and control of aeromedical transport systems during disaster response efforts. Japan has largely developed its current system based on lessons learned from disasters it has had to face. In the aftermath of the 1995 Great Hanshin Earthquake, it was estimated that, despite the efforts of medical staff in the affected area, there were 500 preventable deaths. Only 1 severely injured patient could be airlifted to hospital by FD helicopter on the first day and only 17 in the first 72 hours $^{7-9}$. This clearly highlighted the need for a DMAT and helicopter transport system specialized for medicine that could begin opera- 


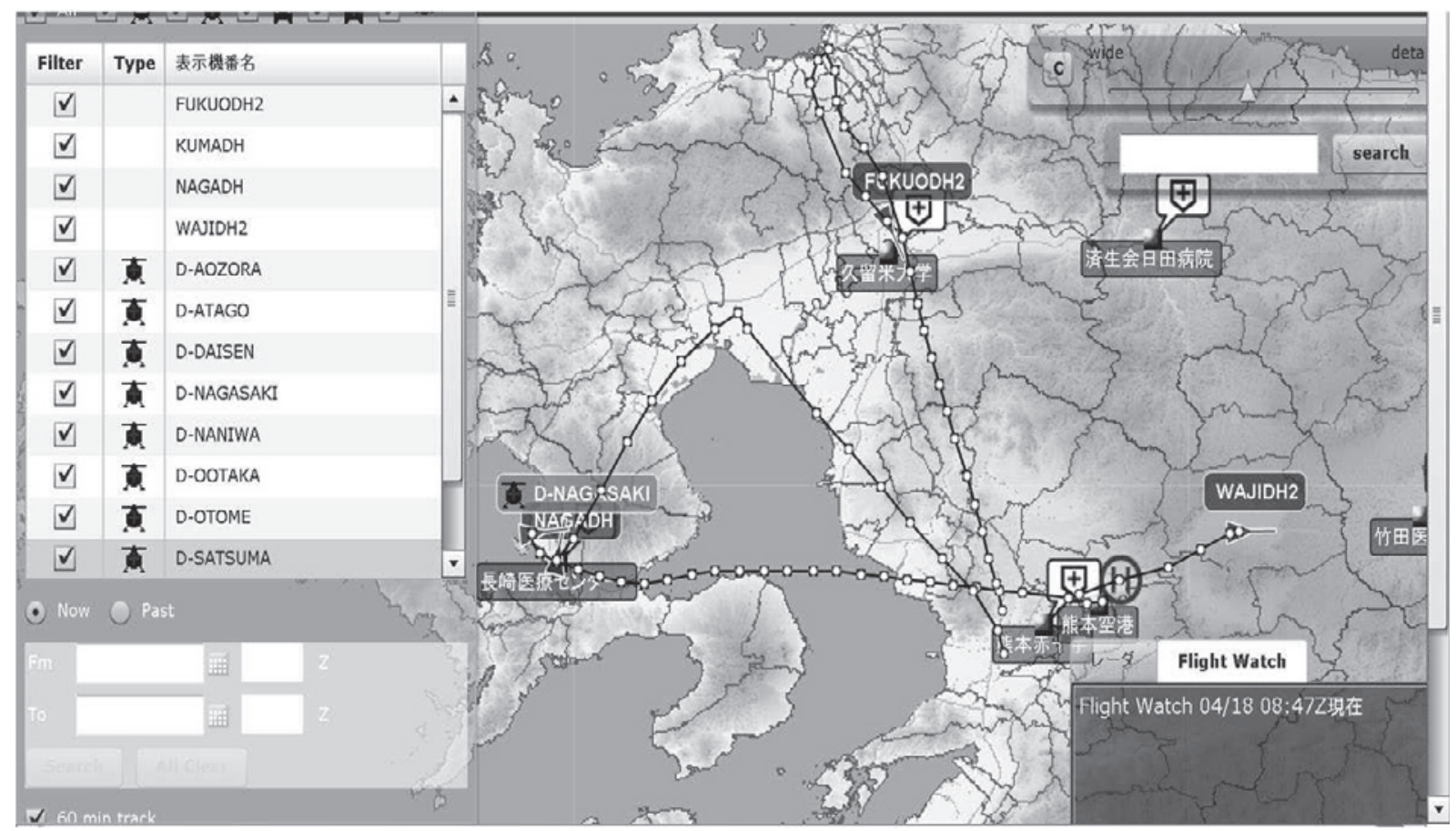

Fig. 5 Information displayed on a laptop by the Disaster Relief Aircraft Management System Network (D-NET). The location of Doctor-Helis and Fire Department helicopters were monitored and shared on this internet site in the aftermath of the 2016 Kumamoto Earthquakes. D-NET helped the DH fleet commander to efficiently control the helicopter operations.

tions in an affected area during the acute phase of a disaster.

The DH system was developed in 2001 based on the lessons learned from the 1995 disaster. DH medical teams dispatched to the scene of emergency situations can stabilize patients and send detailed medical information ahead to the receiving hospital to allow for management on arrival ${ }^{10-13}$, and they have been successfully deployed in Japan in local disaster situations. The study of an efficient method for controlling the DH fleet in disaster situations was started in 2003 and training of DMAT members started in $2005^{14}$. DMAT training includes skills for command and control of medical staff activities, maintaining safety, establishing and maintaining communications using appropriate devices and methods, and providing appropriate transport and disaster medicine both in and outside the affected areas during the acute phase of a disaster. In the Great East Japan Earthquake disaster of 2011, 383 DMATs were involved in activities for 12 days in and outside the affected Tohoku region. At that time, 16 of the total 28 DHs in Japan were assembled in the region and transported 150 patients, including some in hospital evacuation missions, within the first 5 days. Although it is clear that considerable knowledge and new systems developed after the 1995 disaster were extremely useful in the disaster, other problems also be- came apparent ${ }^{1}$. These involved command and control of the DH fleet. There was no commander of the DH fleet in the prefectural government building, and the fleet was not able to share information readily with the SDF, FD, or CG or to officially request use of their helicopters for the most efficient mobilization of aeromedical transport. Also, because the mobile phone network was down as a result of the tsunami, the DH Fleet Commander was not able to obtain enough information or grasp the precise location of the DHs or where the DMAT activities were required and being provided. Thus, it was difficult to efficiently deploy the DHs.

It was after 2011 that the new DH fleet command system, which includes the setting up of DOS in the prefectural government in the affected area, and the multiagency D-NET system were introduced. The research group and DMAT then started national annual joint training using this command and control system between the DH network and the SDF, FD, CG, and Police Department (PD). This resulted in the successful command and control of aeromedical transport using helicopters across multiple organizations in the aftermath of the 2016 Kumamoto Earthquake disaster.

D-NET was first used in an actual disaster situation during the 2016 disaster. It was extremely useful for sharing information about aeromedical transport, which 
helped to effectively control the deployment of the helicopters and maintain safety, by displaying real-time information on laptops about the weather and location of helicopters.

In this study, details about patient outcome were not available and it was not possible to clarify the actual usefulness of the aeromedical transport using $\mathrm{DH}$ or helicopters belonging to other organizations. In this disaster, DMAT, SDF, FD, CG, and PD could talk directly in person within the ACS in the prefectural government office; therefore, multiple organizations were able to cooperate well. Proximity between commanders of multiple organizations is extremely important for communication and cooperation, but the comprehensive layout details of the ACS are not stated in almost all prefectures.

Other ongoing challenges that remain to be addressed concern detailed operational methods to control the use of helicopters for aeromedical transport; for example, procedures and methods for the flow of information on medical demand, information sharing, refueling, insurance for aviation company staff who fly the DHs, and procedures for wireless communication and air traffic control at the air transport bases. It has also been recognized that exchanging the latest knowledge and more training are needed among all of the parties involved in disaster response. Also, other issues should be considered, such as handling limited resources. For example, prioritizing patients for transport and matching patients with the best mode of transport (e.g., DH or ground transport) are difficult and important issues to address.

Such system improvements must be solved earlier rather than later in Japan, before a Nankai Trough and Tokyo inland earthquake occurs as expected in the near future.

\section{Conclusion}

Aeromedical transport using helicopters in disaster situations was developed from 1995 in Japan and was utilized most recently in the 2016 Kumamoto Earthquake disaster. Numerous successful deployments were made in cooperation with helicopter resources of other organizations. DOS operating from the prefectural government and D-NET developed after 2011 were particularly useful for sharing information on patient transportation between DMAT members and with other organizations. The involvement of national headquarters of the $\mathrm{DH}$ fleet, located in the DMAT Secretariat, was also very important for coordination among multiple prefectures and areas. In preparation for large-scale disasters to come, the operations system for helicopters, which are rare and precious resources, must be improved through cooperation between the various organizations that own helicopters.

Conflict of Interest: No potential COI to disclose.

\section{References}

1. Matsumoto H, Motomura T, Hara Y, Masuda $Y$, Mashiko $\mathrm{K}$, Yokota $\mathrm{H}$, Koido $\mathrm{Y}$ : Lessons learned from the aeromedical disaster relief activities following the great east Japan earthquake. Prehosp Disaster Med 2013; 28: 166-169.

2. Martchenke J, Lynch T, Pointer J, Rooker N: Aeromedical helicopter use following the 1989 Loma Prieta earthquake. Aviat Space Environ Med 1995; 66: 359-363.

3. Masoud SN, Nahid N, Yashar M: Survey of Bam earthquake survivors' opinions on medical and health system services. Prehosp Disaster Med 2008; 23: 263-268.

4. Xu L, Yuan L, Lulu Z, Wannian L, Zenghong Z, Yan S, Peng K, Zhipeng L: Mass aeromedical evacuation of patients in an emergency: experience following the 2010 Yushu earthquake. J Emerg Med 2013; 45: 865-871.

5. Cabinet Office, Government of Japan. Report on damage following the Kumamoto Earthquake 2016. http://www.b ousai.go.jp/updates/h280414jishin/pdf/h280414jishin_37. pdf. Accessed January 27, 2017. (in Japanese).

6. Okuno Y, Kobayashi K, Ishii H: Development of a helicopter operations management system for disaster relief missions. J Am Helicopter Society 2016; 61: 1-9.

7. Tanaka H: Overview of evacuation and transport of patients following the 1955 Hanshin-Awaji earthquake. J Emerg Med 1998; 16: 439-444.

8. Kuwagata Y: Analysis of 2,702 traumatized patients in the 1995 Hanshin-Awaji earthquake. J Trauma 1997; 43: 427432.

9. Ukai T: The Great Hanshin-Awaji Earthquake and the problems with emergency medical care. Ren Fail 1997; 19: 633-645.

10. Matsumoto H, Mashiko K, Hara Y, Sakamoto Y, Kutsukata N, Takei K, Tomita Y, Ueno Y, Yamamoto Y: Effectiveness of a "Doctor-Helicopter" system in Japan. Isr Med Assoc J 2006; 8: 8-11.

11. Nicholl JP, Brazier JE, Snooks HA: Effects of London helicopter EMS on survival after trauma. Br Med J 1995; 311: 217-222.

12. Schiller WR, Knox R, Zinnecker $H$, Jeevanandam $M$, Sayre M, Burke J, Young D: Effect of helicopter transport of trauma victims on survival in an urban trauma center. J Trauma 1988; 28: 1127-1134.

13. Cunningham P, Rutledge R, Backer C, Clancy T: A comparison of the association of helicopter and ground ambulance transport with the outcome of injury in trauma patients transported from the scene. J Trauma 1997; 43: 940-946.

14. Kondo H, Koido $\mathrm{Y}$, Morino K, Homma M, Otomo $\mathrm{Y}$, Yamamoto Y, Henmi H: Establishing disaster medical assistance team in Japan. Prehosp Disaster Med 2008; 24: 556-564.

(Received, August 29, 2017) (Accepted, November 1, 2017) 